\title{
Apresentando o PRISE:um processo para conduzir as extensões do iStar
}

\author{
Enyo Gonçalves ${ }^{1,2}$, Jaelson Castro ${ }^{2}$ and João Araújo ${ }^{3}$ \\ ${ }^{1}$ Universidade Federal do Ceará, Campus Quixadá \\ ${ }^{2}$ Universidade Federal de Pernambuco (LER-UFPE), Recife \\ ${ }^{3}$ Universidade Nova de Lisboa (NOVALINCS-UNL), Recife \\ enyo@ufc.br, jbc@cin.ufpe.br, joao.araujodfct.unl.pt
}

Resumo. iStar é uma linguagem de modelagem baseada em objetivos usada para modelar requisitos. Ela vem sendo utilizada em projetos acadêmicos e industriais. Frequentemente o iStar é estendido para incorporarnovos construtores de alguma área de aplicação específica. Atualmente, a linguagem está sobre padronização e diversos estudos tem focado em analisar as variações existentes da linguagem para identificar similaridades e definir um núcleo para iStar. Entretanto, nós acreditamos que ela continuará a ser estendida, assim é importante entender como iStar é extendido e propor mecanismos que ajudem nesta tarefa. Em trabalhos anteriores nós analisamos por meio de uma Revisão Sistemática de Literatura e de um estudo qualitativo como as extensões vem sendo feitas. Atualmente Este video contribui para este propósito apresentando um processo para conduzir as extensões de iStar.

Link para o vídeo: https://youtu.be/Ivon6EYElEg

\section{Agradecimentos}

Os autores agradecem ao CNPQ (Conselho Nacional de Desenvolvimento Científico e Tecnológico), Universidade Federal do Ceará, LER-UFPE e NOVA LINCS/UNL.

\section{Referências}

1. CAIRE, P., GENON, N., HEYMANS, P., MOODY, D. (2013) Visual notation design 2.0: Towards user comprehensible requirements engineering notations. 21 st IEEE International Requirements Engineering Conference (RE).

2. GONÇALVES, E., CASTRO, J., ARAUJO, J., HEINECK, T. A Systematic Literature Review of iStar extensions. Journal of Systems and Software, v. 137, p. 1-33, 2018.

3. GONÇALVES, E., DE OLIVEIRA, M., MONTEIRO, I., CASTRO, J., ARAÚJO, J. Understanding what is important in iStar extension proposals: the viewpoint of researchers, Requirements Engineering Journal, 2018.

4. MOURATIDIS, H., ISLAM, S., KALlONIATIS, C., GRITZALIS, S. (2013) A framework to support selection of cloud providers based on security and privacy requirements, Journal of Systems and Software. 